\title{
The influence of internal and external pressures on carbon management practices and disclosure strategies
}

\begin{abstract}
As a result of institutional and stakeholder pressures, companies have increasingly implemented various internal and external carbon management practices, reflecting different carbon disclosure strategies. Existing research, however, is limited to distinguish between different types of carbon disclosure strategies and to explain the dynamic interaction between internal and external pressures. In response, drawing from institutional and stakeholder theory, this study (1) proposes a framework that depicts different carbon disclosure strategies based on internal and external pressures, and (2) using a sample of 40 leading global logistics companies, subsequently categorises the companies based on the extent of applied internal and external carbon management practices. Using data from Bloomberg ESG and the Carbon Disclosure Project (CDP) reports, the analysis and the categorisation is based 26 specific carbon management practices during the timeframe from 2012 to 2014. The findings show that the majority of companies align internal and external carbon management practices, reflecting a consistent strategic approach towards carbon disclosure. However, most companies follow either a transparent or a symbolic approach, indicating these companies either are engaged in both internal and external practices or in neither. We found that the key internal drivers are the companies' policies and procedures, while key external drivers include high engagement with policy makers and NGOs.
\end{abstract}

Keywords: carbon management practices, carbon disclosure strategies, stakeholder pressures, institutional pressures, logistics

\section{Introduction}

In recent years, global logistics companies have engaged in an increasing number of voluntary climate change initiatives (Herold \& Lee 2017a; Kolk et al. 2008; Schaltegger \& Csutora 2012) in response to growing institutional and stakeholder pressures to reduce carbon emissions and increase transparency (de Villiers \& Alexander 2014; Lee \& Vachon 2016; Lee \& Herold 2016; Luo 2017; Welbeck 2017; Herold et al. 2016). Companies respond to such pressures by disclosing carbon related information aimed at internal audiences (e.g. board members, employees) as well as those that target audiences external to the organisation (e.g. business partners, nongovernmental organisations). For instance, United Parcel Service (UPS) formalises its internal carbon management strategy through five principles in its 'Sustainability Report' while also undertaking several external actions to communicate to key stakeholders and capital market participants the objectives and outcomes of that strategy (Lee \& Vachon 2016; Herold \& Lee, 2018).

Responding to institutional and stakeholder pressures through carbon disclosure is increasingly considered as a key strategic determinant for the company's long-term sustainability of global 
logistics companies (CDP 2010; Hrasky 2011; Lee et al. 2016; Massa et al. 2015), with disclosure of carbon related information either taken proactively to mitigate the risk of potential stakeholders' backlash or retroactively to integrate stakeholders' demands and expectations into the company's operations, structures and processes (Borghei et al. 2016; de Villiers et al. 2011; Hawn \& Ioannou 2016; Herold \& Lee 2017b; Dobrovnik et al. 2018). However, given the wide range of approaches to the mix of internal and external carbon management practices (see e.g. Gibassier \& Schaltegger 2015; Hrasky 2011; Kolk et al. 2008; Herold 2018), the key issue of how the dynamic interaction between external and internal carbon management practices may be associated with a company's carbon disclosure strategy remains unanswered. Therefore, this study addresses this gap by asking the following questions:

RQ1. "How do internal and external pressures influence corporate carbon disclosure strategies?”

To answer this question and to understand the implications of these multiple pressures, this study builds a model to distinguish between internal and external influences based on institutional and stakeholder theory and its constructs. However, in order to categorise carbon disclosure strategies, a more detailed investigation of internal and external carbon management practices is required. Therefore, the following sub-questions are addressed:

\section{RQ1a. "To what extent do specific internal and external carbon management practices influence corporate carbon disclosure strategies?”}

\section{RQ1b. "What carbon disclosure strategies have been adopted from a corporate perspective?"}

Our main theoretical focus is the distinction between internal and external pressures and how the interaction between them influences carbon disclosure strategies. To categorise the internal and external pressures as well as carbon disclosure strategies, we develop an integrative model based on underlying constructs within institutional and stakeholder theory. We argue that internal carbon management practices are influenced by the extent of dissemination of sustainability and climate change values within the organisation, representing structural change, i.e. by drawing on institutional theory, we examine how 'central' (Besharov \& Smith 2014) the sustainability logic is integrated into the company's value system (Thornton \& Ocasio 2008). For external carbon management practices, we argue that these are influenced by the salience of stakeholders, i.e. by drawing on stakeholder theory (Freeman 1983), we examine to which extent carbon disclosure claims from stakeholders are given priority (Mitchell et al. 1997). Based on the relative degree of the combined internal and external influences, we propose four types of carbon disclosure strategies: Excellence, Acquiescence, Compromise and Avoidance. The 'Excellence' carbon disclosure approach represents a company's focus on both internal and external activities, while an 'Acquiescence' approach focuses on internal initiatives only. In contrast, a 'Compromise' approach represents a focus on external activities only, while an 'Avoidance' approach represents a lack in both internal and external activities. 
In order to measure the company's carbon disclosure strategy, we use a dataset from Bloomberg ESG and the associated data from Carbon Disclosure Project (CDP) reports, which allows us to conduct a company comparison and categorisation. Our sample includes 40 global logistics companies that disclosed their carbon-related initiatives and activities to both Bloomberg ESG as well as to CDP, comprising 3120 observations over three years (2012 to 2014). Methodologically, we introduce a novel empirical analysis using 26 specific carbon management practices (CMPs) from Bloomberg ESG and CDP data to calculate scores for the categorisation of carbon disclosure strategies according to the four types in the model.

The contribution of this article is twofold. First, we conceptualise a model of carbon disclosure strategies that proposes four ideal types, thus providing an understanding of the dynamic interaction between internal and external management practices and their influence on carbon disclosure strategies. Second, we empirically categorise carbon disclosure strategies within the global logistics industry, thereby advancing the literature on strategic carbon management and disclosure and providing a tool to assess a company's carbon disclosure position. Thus, this study presents a more nuanced empirical, as well as theoretical, understanding of the mechanisms through which internal and external carbon management practices influence carbon disclosure strategies.

\section{Internal and external pressures}

Carbon disclosure can be regarded as a response to a potential legitimacy gap, which can be defined as "where corporate performance remains unchanged, but societal expectations about that performance have changed" (Hrasky 2011, p.177). For example, global logistics companies as facilitators for global trade, face a heightened legitimacy gap, as the extensive use of the logistics and transportation network depends heavily on fossil fuels and results in high carbon emissions, leading to multiple pressures to reduce the negative impact on the environment (Herold \& Lee 2017b; Onghena et al. 2014).

In order to gain legitimacy and maintain their social license to operate, companies usually follow two ways: internally focused actions and externally focused actions (Hawn \& Ioannou, 2016; Lee \& Herold 2018). The former is aimed at achieving structural change, e.g. structural mimicry or the implementation of certain of accepted and appropriate organisational practices or structures while the latter aims to gain organisational endorsement by external stakeholders. The distinction between internal and external actions can be linked theoretically to institutional theory (e.g. Ansari et al. 2013; Besharov \& Smith, 2014) and stakeholder theory (Freeman, 1983). While internal actions reflect to what extent certain institutional logics are integrated inside the boundaries of the company (i.e. management, owners, employees), external actions reflect the extent of influences from stakeholders outside of the organisation (i.e. government, customers, suppliers, investors). Further, Hawn and Ioannou (2016) argue that both internal and external actions may generate legitimacy: whereas internal actions signal conformity with legitimized structures and thus help organisations gain legitimacy, external actions target particular audiences that confer legitimacy

upon the organization (e.g., through their public endorsement). Legitimacy has long been 
acknowledged as important for the survival of any organisation (e.g. Ansari et al. 2013; de Villiers \& Van Staden 2011; Dowling \& Pfeffer 1975; Herold \& Lee 2017c), it is therefore crucial to distinguish between the two types of internal and external actions and pressures to understand how they influence carbon disclosure strategies.

\section{Internal practices}

Based on the discussion above, the reaction to internal pressures represent inward-looking practices that involve organisational steps to develop organisational capabilities and to meet the expectations of those internal actors upon which the organisation depends for critical resources (Hawn \& Ioannou 2016; Meyer \& Rowan 1977). In the context of carbon disclosure, the set of internal practices may include the implementation of climate change policies or energy-reducing initiatives as well as forming a board-level sustainability committee. As such, the extent of applied or implemented carbon management practices within the organisation can be regarded as an indicator for the overall company’s carbon disclosure strategy.

From an institutional logics perspective, the extent of implemented internal carbon management practices can be related to the position of the so-called sustainability logic within the organisation (Herold \& Lee 2017b). In other words, the extent of internal carbon management practices depends on how the sustainability logic can manifest itself as a core feature that is central to the organisational functioning, and is what Besharov and Smith (2014) call the 'centrality' of an institutional logic in the field. The positioning of sustainability logic, however, varies between companies, as the differences in carbon disclosure approaches indicate (CDP 2010; Schaltegger \& Csutora 2012). While some companies have integrated climate change into their policies to reduce carbon emissions, others are more restrictive in providing carbon-related information, and rely more on 'Avoidance' or symbolic management strategy (Hrasky 2011). Thus, from a theoretical point, the relative position of the sustainability logic to the company core functions influences the extent of carbon disclosure and its applied internal carbon management practices, and may represent different carbon disclosure strategies.

\section{External practices}

In reaction to external pressures, companies engage in public and visible activities as well as in communication tactics that involve the presentation of ceremonies to persuade stakeholders that the company's operations are legitimate and the company is operating as an environmentally responsible citizen (Hörisch et al. 2014; Hrasky 2011). In particular, inter-organisational networks (Stuart et al. 1999), media attention (Sine et al. 2007) and legitimacy of external ties (Baum \& Oliver 1991) can be regarded as crucial practices to gain legitimacy. In the context of carbon disclosure, the set of external practices may include the verification of the company's emissions through a third party, engagement with business or investor organisations such as the Carbon Disclosure Project (CDP), the acknowledgement of industry guidelines (e.g. GRI guideline) or signatories with international organisations (e.g. United Nations Global Compact). As such, the 
extent of applied or implemented carbon management practices outside the organisation can be regarded as an indicator for the overall company’s carbon disclosure strategy.

From a theoretical viewpoint, the extent of applied or implemented external carbon management practices is conceptually aligned with the degree to which managers give priority to competing stakeholders' claims, representing the concept of stakeholder salience in stakeholder theory (Freeman 1983; Mitchell et al. 1997). In a climate change context, the degree of salience depends on the extent to which stakeholders can hold companies accountable for carbon-related practices. Stakeholder salience is high when companies have implemented an open and transparent strategy with the aim of full disclosure, and lower when stakeholder pressure is uncoordinated or can be neglected without serious implications for the company's legitimacy. Thus, from a theoretical point, the relative salience of stakeholders influences the extent of carbon disclosure and its applied external carbon management practices, and may represent different carbon disclosure strategies.

External stakeholders have an indirect influence by applying external pressures to convince internal stakeholders, in particular the company's management, to implement or follow relevant carbon management practices. These dynamics of this relationship represent a constant struggle for power between management and stakeholders outside the company regarding the extent of carbon disclosure and the implementation of carbon management practices. Therefore, we argue that both dimensions - internal pressures on the one hand, as well as external pressures on the other - are critical to determine carbon disclosure strategies.

\section{The implications of carbon disclosure pressures}

We use the dimensions of internal and external pressures to create an integrative model to understand their interaction between internal and external practices on carbon disclosure strategies. The internal perspective reflects how corporate climate change values and principles are exhibited by top management and are shared by organisational members to commit to common corporate environmental goals and aspirations (Linnenluecke \& Griffiths 2010). The external perspective represents the degree of external pressure arising from stakeholders with regard to climate change - that is, how much relevant carbon-related information is disclosed to relevant external stakeholders (Kumarasiri 2017). Thereby, this model provides a conceptual foundation to answer RQ1 ("How do internal and external pressures influence corporate carbon disclosure strategies?") and provides subsequently a framework to analyse and categorise carbon management practices and strategies to answer RQ1a ("To what extent do specific internal and external carbon management practices influence corporate carbon disclosure strategies?") and RQ1b (“What carbon disclosure strategies have been adopted from a corporate perspective?”).

Based on the assumption of potential variation between internal and external responses, we combine these dimensions to propose four types of carbon disclosure strategies. We integrate three strategies of Acquiescence, Compromise and Avoidance in our model that companies may adopt in response to institutional and stakeholder pressures, as proposed by Oliver (1991). However, to reflect the context of carbon disclosure, we extend the view by adding another strategy type called Excellence to illustrate internal and external actions that go beyond institutional pressures and 
market demands. Figure 1 depicts the four types, but it needs to be emphasised that internal and external pressures are dynamic dimensions, and that carbon disclosure can therefore vary between the types. Our framework shows that the extent of carbon-related information depends on internal and external pressures. Below, we describe each type in our model and explain how it implies a distinct level of carbon disclosure.

\title{
Insert Figure 1 around here
}

\author{
Figure 1. Carbon disclosure strategy types
}

\section{Acquiescence}

Organisational acquiescence reflects an organisation's conscious intent to conform to institutional pressures and its expectation that conformity will serve organisational interests (Oliver, 1991). In the context of carbon disclosure, it is argued that related activities reflect the corporate actions taken by a company to achieve carbon-related accomplishments in order to reduce its carbon footprint in line with cost reductions (Hrasky, 2011; Schaltegger and Hörisch, 2015). Because companies have high internal pressures, the integration of climate change values is reflected in organisational structures and is exhibited by top management and shared by organisational members (Linnenluecke and Griffiths, 2010). Moreover, because these companies face low external pressures, there is no need for the company's management to include demands from stakeholders for carbon disclosure beyond market-driven initiatives.

\section{Avoidance}

Avoidance is motivated by the desire to circumvent the conditions that make conforming behaviour necessary (Oliver, 1991). With regard to carbon disclosure, it is argued that this strategy can be related to reputation management, which Schaltegger and Burritt (2015) describe as a company's focus on societal, political and media attention. Because these companies have low internal pressures, carbon-related activities and their disclosure may be closely linked to the public relations department to gain the support of the company's most immediate audiences (Hrasky, 2011). Moreover, because these companies face low external pressures, management may employ self-interested or narcissist behaviour, with claims of carbon-related achievements that are not accompanied by corporate action or that reflect the use of rhetorical statements designed to create an impression of environmental responsibility (Schaltegger and Burritt, 2015). As a result, companies have to deal with uncoordinated action from stakeholders and thus with little demand for full carbon disclosure or to implement carbon-related initiatives that lead to a reduction of the carbon footprint. 


\section{Compromise}

Compromise is employed in the spirit of conforming to and accommodating external pressures, but in contrast to acquiescence, compliance is only partial and organisations are more active in promoting their own interests (Oliver, 1991). In the context of carbon disclosure, we argue that these companies engage in consultations with well-organised stakeholders to discuss the company's carbon-related practices mainly in order to maintain legitimacy. Due to the high external pressures, however, stakeholders will continually ask for accountability regarding carbon emissions, which may include requests to adopt technical, international and industry procedures and to follow well recognised international guidelines such as the GRI guideline (GRI 2016). But because these companies have low internal pressures, they will neglect organisational adaption strategies for climate change and react as little as possible to fulfil only the minimum and mandatory carbon disclosure requirements (Pålsson and Kovács, 2014).

\section{Excellence}

Excellence strategies with regard to carbon disclosure rely on the assumption that the climate change values and principles exhibited by top management will be shared widely and held by all organisational members, leading to a unity among organisational members that fosters a sense of identity and commitment to common corporate carbon-related goals and aspirations (Linnenluecke and Griffiths, 2010). From a stakeholder perspective, the high external pressures reflect an approach aimed at making carbon information more transparent by an active engagement to work on the standards of carbon-related activities in the logistics industry (UNEP/SustainAbility, 2002). This may include the adoption of international guidelines, (e.g. GRI 2016) as well as engagement in public policy climate change activities, working directly with policy-makers, trade associations, research organisations and non-profit organisations (Herzig \& Schaltegger 2011).

\section{Research design}

To address the research aim of understanding the internal and external influences on carbon disclosure strategies, and the subsequent categorisation according the carbon disclosure strategy model, the internal and external carbon management practices of companies needs to be examined. According to Beattie (2014) and Unerman (2000), disclosure indexes are a popular way to quantify the extent of disclosure. We adopt his approach and use a merged dataset from Bloomberg ESG terminals and Carbon Disclosure Project (CDP) reports that includes 26 specific carbon management practices (CMPs) that a company may have adopted. To achieve reliability and validity of the data, we focus on a small sub-set of items (CMPs) as well as on inter-company differences in a specific industry (i.e., global logistics) and use an industry index to measure the disclosure level (Beattie et al. 2004; Botosan 1997). The analysis follows a two-step approach: First, we examine to what extent the internal and external practices of each company are applied or implemented. An analysis of these specific CMPs will allow us to understand the interaction between internal and external practices and provides the foundation for the second step: the categorisation of companies according to the carbon disclosure strategy model. 
Constructing the CMPs as variables to calculate and categorise carbon disclosure strategies is a novel contribution of this study. The dataset were the most up-to-date data available and covers the timeframe from the years 2012 to 2014. The complete dataset contained 3120 corporation-year observations of CMPs. The sample as well as a detailed description of the measurement of carbon management practices and disclosure strategies are given below.

\section{Sample}

The sample of the study focuses on global logistics companies, representing an own industry or an organisational field (Scott 1991), and thus providing homogeneous results that can be compared. The sample comprises the 50 world largest logistics companies in the year 2015, as measured by gross revenues (Journal of Commerce 2015). Collectively, these 50 companies generated nearly US $\$ 230$ billion in annual revenues. Corporate data of variables were retrieved from Bloomberg terminals, providing environmental, social and governance (ESG) information. In particular, Bloomberg provides ESG data for more than 9000 companies worldwide (Bloomberg 2016), including access to data from the Carbon Disclosure Project (CDP). The final sample of the study included 40 global logistics companies, as ten companies were excluded from the sample because the carbon disclosure data was not sufficient for comparison within the global logistics industry.

\section{Carbon disclosure variables}

To measure the internal and external influences, we used 26 carbon management practices (CMPs) from the Bloomberg ESG and CDP dataset that may have been implemented by the global logistics companies. Table 1 describes these CMPs in detail, and distinguishes between internal and external influences.

\section{Insert Table 1 about here}

Table 1. Carbon management practices (CMPs)

\section{Measuring carbon management practices (CMPs)}

In order to examine the carbon management practices, the 26 CMPs were grouped into six broader management sections to measure "the intensity of concern with each category" (Weber, 1990, p.39), three covering the internal influences: 'Structure and Accountability (SA)', 'Policies and Processes (PP)', 'Carbon Assessment (CA)', and three covering the external influences: 'Verification and Assurance (VA)', 'Stakeholder Engagement (SE)', 'Perception and Awareness 
(PA)' (see Table 1). These six broader management sections are also used to calculate scores from the associated CMPs to indicate a specific strategy type for the categorisation of the studied companies.

For each CMP, a score between 0 and 1 was awarded, as a wide range of CMPs in the dataset was analysed by using a 'yes/no' (or 1/0) scoring approach. Where necessary, we re-scaled the scoring ranges in the raw data between 0 and 1 . In our analysis, we interpret a zero CMP score as the absence of that practice from the company's overall carbon management strategy during the years the scores were assigned. The scores refer to the state of corporate management practices from 2012 to 2014, averaging the score in during that timeframe. We interpret a non-zero as the presence of the practice within this timeframe, thus the more often a practice is applied in the timeframe, the higher the score. This makes the scoring ranges of the CMPs and management sections comparable and provides a solid foundation to answer the sub-question RQ1a. ("To what extent do specific carbon management practices influence corporate carbon disclosure strategies?”).

\section{Carbon disclosure strategy measurement}

To answer the second sub-question RQ1b. ("What carbon disclosure strategies have been adopted from a corporate perspective?"), we take the aggregated scores from the three internal and three external management sections to form an overall disclosure score for internal practices and external practices. The overall disclosure scores provide the foundation to categorise the influence of carbon management practices on disclosure strategies of each company.

To categorise the four different carbon disclosure strategy types based on the extent to which internal and external CMPs are applied, we distinguish whether the internal or external CMPs are applied to 'greater extent' or to a 'lesser extent'. To measure the extent of each CMPs, we build an industry average from six management sections (see, e.g. Botosan 1997) based on the available data from the sample and use the aggregated scores to categorise the extent of the applied internal CMPs and external CMPs.

For instance, to categorise the extent of internal CMPs (i.e. to which degree climate change values are disseminated within the organisation), every company that is below the industry average is considered to have implemented internal CMPs to a lesser extent, placing them either in Avoidance or Compromise type, depending on the external CMP scores. Every company that is above the industry average is considered to have implemented internal CMPs to greater extent, placing them either in the Acquiescence or Excellence type, depending on the external CMP scores. To categorise the extent of external CMPs (i.e. to which degree stakeholder claims are given priority), every company that is below the industry average is considered to have followed external CMPs to a lesser extent, placing them either in the Avoidance or Acquiescence type, depending on the internal CMP scores. Every company that is above the industry average is considered to have followed external CMPs to a greater extent, placing them either in the Compromise or Excellence 
type, depending on the external CMP scores. As this calculation is based on multiple criteria, the cumulative scores place each company individually in a different quadrant.

\section{Results}

\section{Descriptive statistics of CMPs}

Table 2 presents a summary of the descriptive statistics for all applied carbon management practices and the aggregated data, including the mean, standard deviation, minimum and maximum.

\section{Insert Table 2 about here}

\section{Table 2. Summary of descriptive statistics}

We focused on the key patterns that emerged from our analysis. Regarding the overall scores of CMPs, the internal CMPs with a score of 0.49 show that global logistics companies have, on average, implemented almost half of the practices studied. For the external CMPs with a score of 0.48 , we can see a similar result, which means that global logistics companies have reacted to external pressures by adopting also almost half of the practices. While both internal and external scores are similar, differences in the management sections and specific CMPs can be observed.

For external CMPs, for instance, stakeholder engagement (SE) with a score of 0.55 has a greater impact on the overall external CMPs score than verification and assurance (VA) with score of 0.39. In this context, a closer look at the specific CMPs reveals that the overall score of verification and assurance (VA) is heavily influenced by a low score for Scope 3 emissions and the lack of verification from a third party. The score of stakeholder engagement (SE) is mainly driven by an engagement with policymakers (0.54), but even more being a signatory of the United Nations Global Change agreement (0.81). Interestingly, only a minority of the global logistics companies use the GRI framework (0.09).

A closer look at the internal CMPs reveals that structure and accountability (SA) with a score of 0.38 has a lower impact on the overall internal CMPs than policies and processes (PP) with a score of 0.65. A more detailed investigation of the score in structure and accountability (SA) shows that the low overall score stems from the sub-categories 'executive and non-executive director for sustainability' with a score of 0.09 and 0.00 , respectively, i.e. most companies fail to appoint an official authority for their sustainable activities. The CMPs of policies and processes (PP) have overall higher scores, but an investigation into the sub-categories shows that the score is mainly 
driven by emissions reductions initiatives (0.81) and energy efficiency policies (0.77), i.e. most companies focus on reducing their carbon footprint and the associated operational costs.

\section{Categorisation of carbon disclosure strategies}

The internal and external CMPs research design allows for a categorisation of the global logistics companies' carbon disclosure strategies according to the extent of implemented or applied 26 CMPs in each company. Following the carbon disclosure model (see Fig. 1), we allocated the companies according to the specific internal and external CMPs into the four types Excellence, Acquiescence, Compromise and Avoidance. For each company, we calculated an aggregated internal score based on the CMPs from the internal dimension as well as an aggregated score based on the CMPs from the external dimension. These scores were compared to an industry index from

the six management sections based on the available data from the sample, which allows a categorisation into the four different carbon disclosure types based on the extent of applied CMPs.

For instance, if a company has implemented internal CMPs to a lesser extent (i.e. their score is below industry average) and followed external CMPs to a lesser extent (i.e. their score is below industry average), the company will be placed in the Avoidance type. In contrast, if a company has implemented internal CMPs to a greater extent (i.e. their score is above industry average) and followed external CMPs to a greater extent (i.e. their score is above industry average), the company will be placed in the Excellence type. The results are shown in Fig. 2, where we placed each company based on their respective internal and external CMPs score. Out of the 40 companies, 35 per cent $(n=14)$ of the sample were allocated into the Avoidance type, 15 per cent $(n=6)$ were allocated into the Acquiescence type, 5 per cent $(n=2)$ were allocated into the Compromise type, while the remaining 45 per cent $(n=18)$ were allocated into the Excellence type.

\section{Insert Figure 2 about here}

\section{Figure 2. Summary of the global logistics companies' carbon disclosure strategies}

The results show the 80 per cent of the studied global logistics companies follow either Excellence strategies or Avoidance strategies in their carbon disclosure. In other words, the majority of companies which have implemented internal practices to a greater extent, have followed external practices also to a greater extent and vice versa, i.e., companies which have implemented internal practices to a lesser extent, have also drawn lesser attention to external practices. In contrast, only the remaining 20 per cent show a mix consisting of either a greater focus on internal practices than 
on external practices or a greater external engagement in conjunction with lesser emphasis on internal practices.

To understand the drivers behind the carbon disclosure strategies, we performed an analysis of the internal and external management sections per carbon disclosure type. The results can be found in Table 3. The results show significant differences between the applied carbon management practices within global logistics companies. For instance, for companies with Excellence strategies, policies and procedures (PP) are the main driver (with a score of 0.94) for the high score of internal CMPs, while stakeholder engagement (SE) with a score of 0.79 and verification and assurance (VA) with a score of 0.72 are the drivers within external CMPs. Companies with Avoidance strategies show extreme weak results in external verification and assurance (VA) with a score of 0.08 , but have also low scores internally in the structure and accountability (SA) as well as climate change assessment (CA) with a score of 0.20 each. Companies with Compromise strategies are driven by a high score in perception and awareness (PA) with a score of 0.84, but show weak results in verification and assurance (VA) with a score of only 0.33 . For companies

with Acquiescence strategies, policies and processes (PP) with a score of 0.64 are the main driver for internal activities, but these companies show overall strong scores for the internal CMPs with a score of 0.50 in structure and accountability (SA) and a score of 0.56 in climate change assessment (CA).

\section{Insert Table 3 about here}

Table 3. Scores by carbon disclosure strategy type

The categorisation into different carbon disclosure types and the subsequent analysis of the CMP drivers allows for a discussion and interesting insights into the mechanisms behind the strategies of global logistics companies.

\section{Discussion}

The results provide an interesting insight into the carbon disclosure strategies of global logistics companies. In order to gain a comprehensive understanding of both the impact of the specific CMPs and the associated type of carbon disclosure strategies within the global logistics industry, the discussion will focus on how the extent of the dynamic interaction between internal and external practices influences carbon disclosure strategies. One of the key findings of this study is that 80 per cent (32 out of 40) of global logistics companies follow a consistent approach regarding 
the applied internal and external practices. In particular, 18 companies, that have implemented internal CMPs to greater extent are also externally engaged to greater extent, thus following an Excellence carbon disclosure approach. In contrast, 14 companies which have implemented CMPs to a lesser extent, are also less engaged externally, thus following an Avoidance carbon disclosure approach. This indicates that the majority of companies either follow an Excellence approach, having adopted a carbon disclosure strategy that is consistent with internal and external actions, or have adopted an Avoidance strategy, following an inconsistent approach in both external and internal activities.

In particular, global logistics companies representing the Excellence type have implemented energy and emission-reductions policies to greater extent with a high score of 0.94 in policies and procedures (PP). According to Oberhofer and Dieplinger (2014), most carbon footprint reductions are linked directly to improving operational efficiency and fuel savings and internal carbon and energy-reducing initiatives are key drivers for operational excellence. From an external perspective, these companies engage actively with policy makers and non-profit organisations, represented by the high score of 0.79 in stakeholder engagement (SE). Another indicator is the higher score in the section verification and assurance (VA) with 0.72 , which is line with the findings of Herzig and Schaltegger (2011), who found that Excellence behaviour and full accountability is linked to the adoption of technical and industry procedures and official international guidelines (e.g. GRI, 2016).

In contrast, global logistics companies representing the Avoidance type seem to have no consistent carbon disclosure strategy integrated in their organisation or their activities are not consistent with their strategic approach. Their overall low scores indicate that they face no or little perceived external pressures to follow or implement CMPs. This is in line with Hrasky (2011), who found that companies that follow an Avoidance strategy do not take corporate actions, but rather use rhetorical statements designed to create an impression of environmental responsibility. In particular, our findings show that the companies in the Avoidance type have implemented policies and procedures (PP) to a lesser extent (0.37), but have also neglected to establish formal oversight in their organisational structure.

The findings are also interesting from a theoretical view. For Excellence companies, the implementation of internal CMPs reflects the position of the sustainability logic as a core function and the company's organisational culture of climate change values. At the same time, it seems these values are transferred to the external dimension where the high salience represents the company's approach to give priority to stakeholder claims that go beyond market-driven initiatives, leading to transparency and full carbon disclosure.

On the other hand, the alignment between internal and external practices is also present in the Avoidance type. Here, global logistics companies that have implemented internal CMPs to lesser extent, which indicates that the dominant market logic leads to a negligence of the sustainability logic and thus to little internal actions to integrate climate change values. It seems that the lack of 
climate change values within the organisation is also reflected in the external engagement, neglecting stakeholder claims for full disclosure. It could also be argued the lack of external activities has a direct impact on the internal initiatives in global logistics companies. In other words, unless global logistics companies communicate and engage with stakeholders in a consistent and credible manner, external audiences can assume that the company is not sufficiently engaged in internal activities.

\section{Conclusions}

Our analysis revealed interesting findings regarding the extent of applied carbon management practices and the associated categorisation of carbon disclosure strategies. One key finding is that within the global logistics industry, the majority of companies follow a consistent strategic approach regarding their internal and external carbon management practices, i.e. they either are engaged on both dimensions or in neither. We found that the key driver within internal CMPs are the companies' policies and procedures, e.g. policies regarding emissions or energy reductions, while key driver within external CMPs include a high engagement with policy makers and NGOs. These findings extend prior work on structural change and describe the interaction between internal and external pressures, which is key step towards a more detailed understanding of the mechanisms that influence carbon disclosure strategies.

Within the strategic carbon management and disclosure literature, we contribute to the stream of work in three ways. First, based on critical constructs drawn from institutional and stakeholder theory conceptualised, we decouple internal and external management practices to conceptualise a model of carbon disclosure strategies that proposes four ideal types, thus providing a theoretical foundation to examine the dynamic interaction between these practices and their influence on carbon disclosure. Second, we categorised the carbon disclosure strategies within the global logistics industry and analysed the key drivers of carbon management practices, thus providing empirical evidence within an organisational field regarding environmental and carbon disclosure strategies. This study demonstrated that institutional as well as stakeholder theory provide, on different levels, a foundation to examine and understand the mechanisms through which internal and external carbon management practices influence carbon disclosure strategies.

However, there are certain limitations in our study that we hope will provide opportunities for future research. First, although our Bloomberg ESG and the associated CDP data provide a sufficient overview about carbon management practices, both datasets impose certain limitations due to the relatively new data and the limited timeframe. Future research could include datasets that provide data over a longer period, thus providing the opportunity to examine if carbon disclosure strategies have changed and identify the drivers behind that change. Second, while this study establishes a clear distinction between internal and external practices to measure the impact within the global logistics industry, we acknowledge that the sample is limited and the results can be hardly generalised. We are thus cautious about making any causal claims. Third, we examined 
carbon management and disclosure practices through institutional and stakeholder lenses. Future research could include other theoretical lenses and constructs. For example, within the construct of institutional logics, we focused on the market logic and the sustainability logic, but companies face multiple pressures, the market and sustainability logic being only two of them.

Our research also has implications for practice: given increasingly high institutional pressures on global logistics companies to engage more in environmental activities, managers should consider investing in both dimensions, the internal as well as the external one. On the one hand, institutions such as Carbon Disclosure Project (CDP) are drivers to respond internally by integrating carbon management practices into their operations, structures and processes. On the other hand, societal awareness of climate change has also risen and companies need to implement carbon management practices to mitigate the risk of potential stakeholders' backlash and to satisfy external audiences. By distinguishing between internal and external pressures, our study generates a better understanding of carbon disclosure, not only by presenting the drivers behind successful disclosure strategies, but also by identifying the most effective carbon management practices.

\section{References}

Ansari, S, Wijen, F \& Gray, B 2013, 'Constructing a climate change logic: An institutional perspective on the "tragedy of the commons"', Organization Science, vol. 24 no. 4, pp. 1014-1040.

Baum, JA \& Oliver, C 1991, 'Institutional linkages and organizational mortality', Administrative Science Quarterly, vol. 36 no. 2, pp. 187-218.

Beattie, V 2014, 'Accounting narratives and the narrative turn in accounting research: Issues, theory, methodology, methods and a research framework', The British Accounting Review, vol. 46 no. 2, pp. 111-134.

Beattie, V, McInnes, B \& Fearnley, S 2004, 'A methodology for analysing and evaluating narratives in annual reports: a comprehensive descriptive profile and metrics for disclosure quality attributes', Accounting Forum, vol. 28 no. 3, pp. 205-236.

Besharov, ML \& Smith, WK 2014, 'Multiple institutional logics in organizations: Explaining their varied nature and implications', Academy of Management Review, vol. 39 no. 3, pp. 36481.

Bloomberg 2016, 2016 Impact Report, retreived from: <https://data.bloomberglp.com/company/sites/28/2017/05/17_0516_ImpactBook_Final.pdf $>$.

Borghei, Z, Leung, P \& Guthrie, J 2016, 'The nature of voluntary greenhouse gas disclosure-an explanation of the changing rationale: Australian evidence', Meditari Accountancy Research, vol. 24 no. 1, pp. 111-133.

Botosan, CA 1997, 'Disclosure level and the cost of equity capital', Accounting Review, vol. 72 no. 3, pp. 323-349.

CDP 2010, Transport Report, edn, Carbon Disclosure Project, London, $<$ https://www.cdp.net/CDPResults/CDP-Transport-Report.pdf>.

CDP 2011, Investor CDP 2011 Information Request - Deutsche Post AG, edn, Carbon Disclosure Project, London. 
de Villiers, C \& Alexander, D 2014, 'The institutionalisation of corporate social responsibility reporting', British Accounting Review, vol. 46 no. 2, pp. 198-212.

de Villiers, C, Naiker, V \& Van Staden, CJ 2011, 'The effect of board characteristics on firm environmental performance', Journal of Management, vol. 37 no. 6, pp. 1636-1663.

de Villiers, C \& Van Staden, CJ 2011, 'Where firms choose to disclose voluntary environmental information', Journal of Accounting and Public Policy, vol. 30 no. 6, pp. 504-525.

Dobrovnik, M, Herold, DM, Fürst, E \& Kummer, S 2018, 'Blockchain for and in Logistics: What to Adopt and Where to Start'. Logistics, vol. 2 no. 3, 18.

Dowling, J \& Pfeffer, J 1975, 'Organizational legitimacy: Social values and organizational behavior', Pacific Sociological Review, vol. 18 no. 1, pp. 122-136.

Freeman, RE 1983, 'Strategic management: A stakeholder approach', Advances in Strategic Management, vol. 1 no. 1, pp. 31-60.

Gibassier, D \& Schaltegger, S 2015, 'Carbon management accounting and reporting in practice: A case study on converging emergent approaches', Sustainability Accounting, Management and Policy Journal, vol. 6 no. 3, pp. 340-365.

GRI. 2016. Initiatives Worldwide [Online]. Global Reporting Initiative. Available: https://www.globalreporting.org/information/policy/initiativesworldwide/Pages/default.aspx.

Hawn, O \& Ioannou, I 2016, 'Mind the gap: The interplay between external and internal actions in the case of corporate social responsibility', Strategic Management Journal, vol. 37 no. 13, pp. 2569-2588.

Herold, DM, Manwa, F, Sen, S \& Wilde, SJ 2016, 'It's the yeast we can do: Untapping Sustainability Trends in Australian Craft Breweries', Journal of Asia Entrepreneurship and Sustainability, vol. 12 no. 2, pp. 82-110.

Herold, DM \& Lee, K-H 2017a, 'Carbon management in the logistics and transportation sector: An overview and new research directions', Carbon Management, vol. 8 no. 1, pp. 79-97.

Herold, DM \& Lee, K-H 2017b, 'The influence of the sustainability logic on carbon disclosure in the global logistics industry: The case of DHL, FDX and UPS', Sustainability, vol. 9 no. 4, 601.

Herold, DM \& Lee, K-H 2017c, 'Corporate environmental responsibility: focus, orientation and salience in the natural resources sector', International Journal of Global Environmental Issues, vol. 16 no. 4, pp. 254-76.

Herold, DM. 2018. The Influence of Institutional and Stakeholder Pressures on Carbon Disclosure Strategies: An Investigation in the Global Logistics Industry, Doctoral dissertation, Griffith University.

Herold, DM \& Lee, K-H 2018, 'Carbon disclosure strategies in the global logistics industry: Similarities and differences in carbon measurement and reporting ', in Hossain, M, Hales, R \& Sarker, T (eds), Pathways to a Sustainable Economy, Springer, Cham, pp. 87-101

Herzig, C \& Schaltegger, S 2011, 'Corporate sustainability reporting', Sustainability Communication, Springer, pp. 151-169

Hörisch, J, Freeman, RE \& Schaltegger, S 2014, 'Applying stakeholder theory in sustainability management: Links, similarities, dissimilarities, and a conceptual framework', Organization \& Environment, vol. 27 no. 4, pp. 328-346.

Hrasky, S 2011, 'Carbon footprints and legitimation strategies: symbolism or action?', Accounting, Auditing \& Accountability Journal, vol. 25 no. 1, pp. 174-98. 
Journal of Commerce (JOC) 2015, Top 50 Global 3PL Companies, Pittsburgh, PA, $<$ http://www.jindel.com/Newsroom/IndustryData/pdflists/2015_Top\%2050\%20Global\% 20Trans\%20Providers_JOC.pdf $>$.

Kolk, A, Levy, D \& Pinkse, J 2008, 'Corporate responses in an emerging climate regime: the institutionalization and commensuration of carbon disclosure', European Accounting Review, vol. 17 no. 4, pp. 719-45.

Kumarasiri, J 2017, 'Stakeholder pressure on carbon emissions: strategies and the use of management accounting', Australasian Journal of Environmental Management, pp. 1-16.

Lee, K-H \& Vachon, S 2016, Business value and sustainability: An integrated supply network perspective, Palgrave Macmillan, London.

Lee, K-H \& Herold, DM 2016, 'Cultural relevance in corporate sustainability management: a comparison between Korea and Japan', Asian Journal of Sustainability and Social Responsibility, vol. no. pp. 1-21.

Lee, K-H \& Herold, DM 2018, 'Cultural Relevance in Environmental and Sustainability Management Accounting (EMA) in the Asia-Pacific Region: A Link Between Cultural Values and Accounting Values Towards EMA Values', in Lee KH \& Schaltegger S (eds), Accounting for Sustainability: Asia Pacific Perspectives, Springer, pp. 11-37

Lee, K-H, Herold, DM \& Yu, A 2016, 'Small and Medium Enterprises and Corporate Social Responsibility Practice: A Swedish Perspective', Corporate Social Responsibility and Environmental Management, vol. 23 no.2, pp. 88-99

Linnenluecke, MK \& Griffiths, A 2010, 'Corporate sustainability and organizational culture', Journal of World Business, vol. 45 no. 4, pp. 357-366.

Luo, L 2017, 'The influence of institutional contexts on the relationship between voluntary carbon disclosure and carbon emission performance', Accounting \& Finance, pp. 1-30.

Massa, L, Farneti, F \& Scappini, B 2015, 'Developing a sustainability report in a small to medium enterprise: process and consequences', Meditari Accountancy Research, vol. 23 no. 1, pp. 62-91.

Meyer, JW \& Rowan, B 1977, 'Institutionalized organizations: Formal structure as myth and ceremony', American Journal of Sociology, vol. 83 no. 2, pp. 340-363.

Mitchell, RK, Agle, BR \& Wood, DJ 1997, 'Toward a theory of stakeholder identification and salience: Defining the principle of who and what really counts', Academy of Management Review, vol. 22 no. 4, pp. 853-886.

Oberhofer, P \& Dieplinger, M 2014, 'Sustainability in the transport and logistics sector: Lacking environmental measures', Business Strategy and the Environment, vol. 23 no. 4, pp. 236253.

Oliver, C, 1991, 'Strategic responses to institutional processes', Academy of Management Review, vol. 16 no. 1, pp. 145-279.

Onghena, E, Meersman, H \& Van de Voorde, E 2014, 'A translog cost function of the integrated air freight business: The case of FedEx and UPS', Transportation Research Part A: Policy and Practice, vol. 62 no. pp. 81-97.

Pålsson, H \& Kovács, G 2014, 'Reducing transportation emissions: A reaction to stakeholder pressure or a strategy to increase competitive advantage', International Journal of Physical Distribution \& Logistics Management, vol. 44 no. 4, pp. 283-304.

Schaltegger, S \& Burritt, R 2015, 'Business cases and corporate engagement with sustainability: Differentiating ethical motivations', Journal of Business Ethics, pp. 1-19. 
Schaltegger, S \& Csutora, M 2012, 'Carbon accounting for sustainability and management. Status quo and challenges', Journal of Cleaner Production, vol. 36 no. pp. 1-16.

Schaltegger, S \& Hörisch, J 2015, 'In search of the dominant rationale in sustainability management: Legitimacy-or profit-seeking?', Journal of Business Ethics, pp. 1-18.

Scott, WR 1991, 'Unpacking institutional arguments', in Powell, WW \& DiMaggio, PJ (eds), The new institutionalism in organizational analysis, University of Chicago Press, Chicago, pp. 164-182.

Sine, WD, David, RJ \& Mitsuhashi, H 2007, 'From plan to plant: Effects of certification on operational start-up in the emergent independent power sector', Organization Science, vol. 18 no. 4, pp. 578-594.

Stuart, TE, Hoang, H \& Hybels, RC 1999, 'Interorganizational endorsements and the performance of entrepreneurial ventures', Administrative Science Quarterly, vol. 44 no. 2, pp. 315-349.

Thornton, PH \& Ocasio, W 2008, 'Institutional logics', in Greenwood, R, Oliver, C, Suddaby, R \& Sahlin, A (eds), The Sage handbook of organizational institutionalism, Sage, London, vol. 840, pp. 100-129

UNEP/SustainAbility 2002, Trust us: The global reporters 2002 survey of corporate sustainability reporting, UNEP, London.

Unerman, J 2000, 'Methodological issues-Reflections on quantification in corporate social reporting content analysis', Accounting, Auditing \& Accountability Journal, vol. 13 no. 5, pp. 667-681.

Weber, RP 1990, Basic content analysis, quantitative applications in the social sciences, Sage Publications, Beverly Hills, CA.

Welbeck, EE 2017, 'The Influence of Institutional Environment on Corporate Responsibility Disclosures in Ghana', Meditari Accountancy Research, vol. 25 no. 2, pp. 216-240. 